\title{
Simultaneous determination and difference evaluation of volatile components generated from ginseng fruit by HS-SPME Coupled with GC-MS according to fruit color
}

\author{
Lili CUI ${ }^{1}$ (D), Jingying XU², Zhiwei FENG ${ }^{3}$, Meixia YAN ${ }^{1}$, Xiangmin PIAO ${ }^{1}$, Ying YU ${ }^{1}$, Wei $\mathrm{HOU}^{1}$, Yinping JIN ${ }^{1}$, \\ WANG Ying-Ping ${ }^{1 \star}$
}

\begin{abstract}
The volatile components of fruits of Panax ginseng C.A. Meyer analyzed to interpret whether fruits color affect volatile components. The volatile components in ginseng fruits cultured with 3 different clolors such as red fruits, yellow fruits and orange fruits were isolated by head-space solid-phase microextraction fiber (polydimethylsiloxane $100 \mu \mathrm{m}$ ) and identified by gas chromatography mass spectrometry (GC-MS). Then, the volatile components compared by principal component analvsis (PCA). As the results, the 23 voltile components were identified from 3 colors samples and consisted mainly of sesquiterpene hydrocarbons. The differences among the different colors of the samples were obvious from the PC1 and PC2 scatter point plot. As the conclusion, The volatile components of ginseng fruits are different from those of ginseng roots. the fruits colors can affect to produce the volatile components of ginseng fruits.
\end{abstract}

Keywords: panax ginseng; fruits; volatile components; principal component analysis; head-space solid phase microextraction.

Practical Application: Ginseng fruit quality evaluation, development and breeding program of panax ginseng.

\section{Introduction}

The ginseng fruits are dry ripening fruits of Panax ginseng Meyer (Araliaceae). The chemical compositions of ginseng fruits contain ginsenosides, ginseng oil and carbohydrates and sugars, amino acids and allaloids, vitamins and minerals, and certain natural components (Shi et al., 2018; Tao et al., 2018). Among these components, ginsennosides have been regarded as the main active components responsible for the pharmacological activities of ginseng. To date, 37 ginsenosides have been isolated and identified from the fruits of P. ginseng. The pharmacological effects of ginseng have been demonstrated on the cardiovascular, endocrine, and immune systems. In addition, the constituents of ginseng fruit have contributed to anti-neoplastic, anti-arrhythmic, investigation of myocardial ischemia, cerebral ischemia, hypoglycemic, the protective effect of reperfusion injury and liver function (Shi et al., 2018).

Ginseng has a unique scent from its volatile components, which are increasingly recognized to possess properties of aromatic, anti-fugal, sedation, and anti-neoplastic. Volatile components are widely used in the perfume, cosmetic, food and pharmaceutical industries. Analysis of herbal volatiles is a significant and growing area of research. The common extraction methods are mainly based on steam distillation and solvent extraction to isolate volatile oils (Turgumbayeva et al. 2018; Tuan et al. 2019), whose major drawbacks are inefficiency and wasting abundant chemical reagents. In recent years, many new extraction techniques, such as supercritical fluid extraction, solid-phase microextraction, and direct sample injection, have been developed (Abd El-Aty et al., 2010; Bajer et al., 2018; Misharina et al., 2018; Mattje et al., 2019).
As a new technique for sample pretreatment, head-space solid phase microextraction especially fits for extraction and concentration of tracing volatile components. Compared with traditional extraction and purification methods, there are many advantages such as high-efficiency (rapid extraction, convenient), and solvent free. This method has been extensively applied to many fields such as environment, food and medicine (Jiang et al., 2018).

With fruit colors as the classification characteristic, panax ginseng can be divided into yellow, red and orange fruit ginseng that is one of the unique germplasm resources collected in China. Actually, more than 1000 tons of fruit pulp is produced per year in China by obtaining ginseng seeds. In the previous study, the content of ginseng saponins in dried fruits is 4 times that of ginseng root, which is of great significance to its development and utilization. Hence, the purpose of this paper is to explore the technique, HS-SPME coupled with GC-MS, to confirm the volatile components in various colors ginseng fruits, which would promote the development and utilization of ginseng fruits.

\section{Materials and methods}

\subsection{Materials}

The 3 ginseng cultivar (red, yellow and orange fruit) used in the present study were 4-year-old dried fruits. P. Ginseng were cultivated from different cultivation areas in China (Fusong, Jian) and then collected directly from ginseng germplasm resource bases by Institute of Special Wild Economic Animal 
and Plant Science of Chinese Academy of Agricultural Sciences. Chromatographic pure hexane (Fisher Scientific, China), and organic microporous membrane $(0.22 \mu \mathrm{m}$, Dikma Technologies Beijing).

\subsection{Head Space-Solid Phase Microextraction (HS-SPME) procedure}

Red, orange and yellow ginseng fruits with 5-year were collected from Fusong County of Jilin Province in July. The dried ginseng fruits powders in the present study were removed seeds, then dried with hot air $\left(40^{\circ} \mathrm{C}\right)$, sieved through 200 mesh screen, and powders were stored at room temperature until they were analyzed.

In the study, the SPME fibers were $100 \mu \mathrm{m}$ polydimethylsiloxane (PDMS). the powder $1.0 \mathrm{~g}$ was sealed into $20 \mathrm{~mL}$ headspace (HS) vial, the fiber was exposed to the $\mathrm{HS}$ at $70^{\circ} \mathrm{C}$ for $60 \mathrm{~min}$. SPME desorption time into GC injector was $1 \mathrm{~min}$ at the appropriate temperature for each fiber in splitless.

\subsection{GC-MS analysis}

Gas chromatography-mass spectrometry (GC-MS) has the characteristics of high separation efficiency, high sensitivity (up to $10^{-9}$ ) and high selectivity, which identified multi-component mixtures by total ion flow spectra and mass spectra, and accurately quantified by peak matching method and selective ion monitoring method. GC-MS had a widely use in life sciences, environmental protection, materials, food, drug development and other fields, particularly applicable to the analysis of volatile or easily derived from compounds (Costa et al., 2018; Martins et al., 2018; Coutinho et al., 2019; Silveira et al., 2019). The GC-MS analysis were performed on an Agilent model $7890 \mathrm{~N}$ GC equipped with a 5975 electron impact (EI) mass spectral detector (Agilent Technologies, USA). Components were separated on a $30 \mathrm{~m} \times 0.25 \mathrm{~mm} \times 0.25 \mu \mathrm{m} \mathrm{HP}-1$ ( $100 \%$ dimethylpolysiloxane) capillary column. The injector and detector temperatures were 250 and $300^{\circ} \mathrm{C}$, respectively. The oven temperature was held at $60{ }^{\circ} \mathrm{C}$ for $3 \mathrm{~min}$, subsequently increased to $250^{\circ} \mathrm{C}$ at a rate of $5^{\circ} \mathrm{C} / \mathrm{min}$ and was then held constant for $41 \mathrm{~min}$. Injection was performed using a splitless mode. Carrier gas was high-purity helium $(99.9999 \%)$, with a constant flow rate of $1 \mathrm{~mL} / \mathrm{min}$, nominal init pressure of 8.13 psi. The EI-MS was analyzed at an ionization energy of $70 \mathrm{eV}$ at $250{ }^{\circ} \mathrm{C}$. The detection was performed in the scan mode between 20 and $650 \mathrm{amu}$.

\subsection{Identification and quantative analysis}

Identification of the Volatile components was based on comparison of their mass spectra and retention index (RI). Firstly, components were positvly identified with mass spectra of reference components in the NIST mass spectral database (2008 version; National Institute of Standards and Technology, USA), and then the RI of the components were calculated using $n$-alkanes from C7 to C30 asexternal references injected under the same chromatographic conditions. Percentage peak areas were calculated by dividing the ion counts for target components (detected by MS) by the total ion counts (TIC) for the entire chromatogram; The relative area percentage was quantified.

\subsection{Statistical analysis}

Principal component analysis (PCA) was applied to relative peak area values of volatiles obtained on the GC-MS total ion chromatograms by using Multibase (version 2015, Chiyoda Tokyo Japan). The plot for samples was averaged across replicates to aid in interpreting the volatile components and samples.

\section{Results and discussion}

\subsection{Volatile Composition of various color ginseng fruits}

The total ion chromatograms of the samples by HS-SPME method are shown in Figure 1. Table 1 lists the volatile components of ginseng fruits according to fruits colors, with their peak areas on the HP- 1 coloum. A total of 23 volatiles components, including 18 terpenes, 3 terpene alcohols and 2 alkanes, were analyzed in dried ginseng fruits. Test results show that the following sesquiterpenes are the main volatile components in ginseng fruits: (E)- $\beta$-famesene, $\beta$-elemene, santalene, cedrene

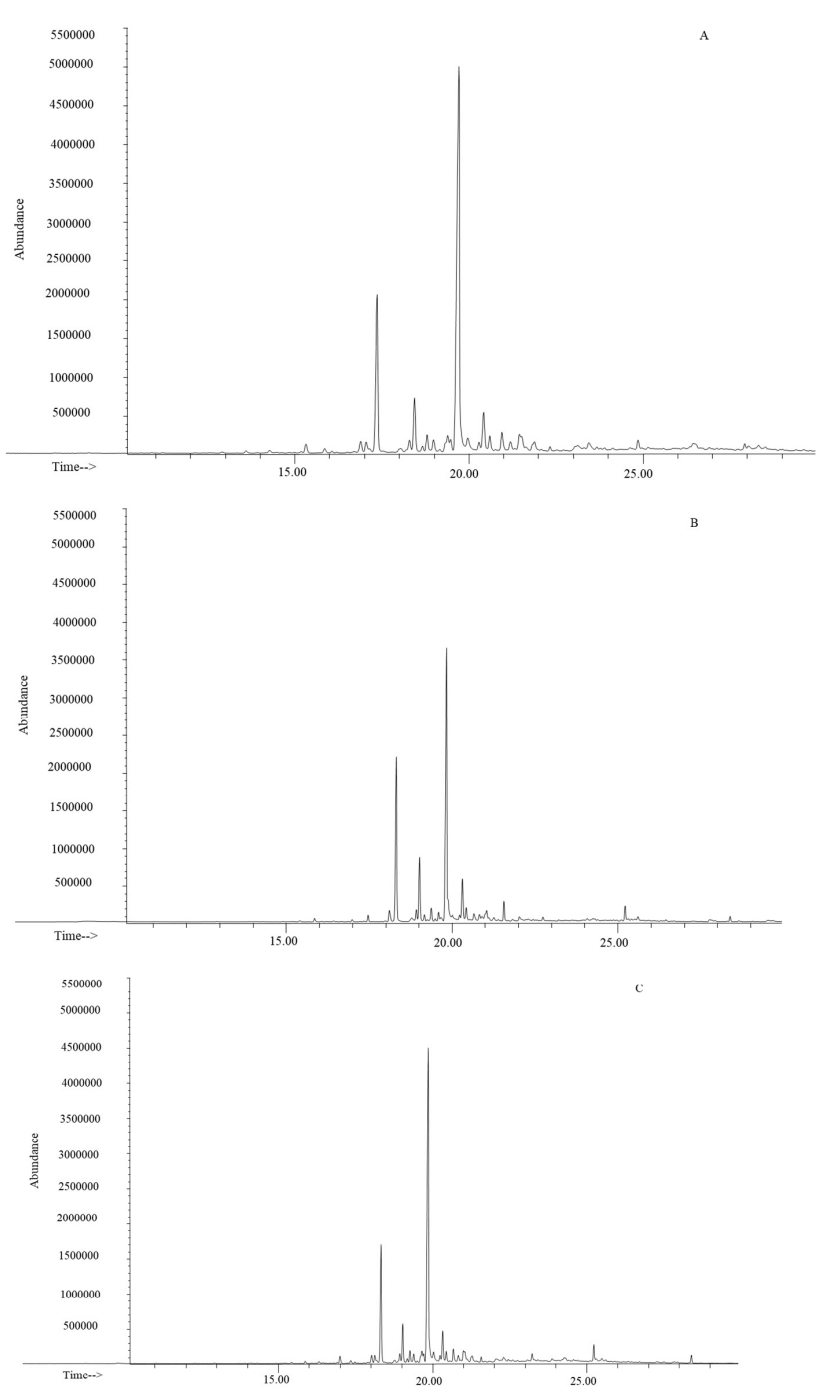

Figure 1. Typical GC-MS chromatograms of volatile flavor components extracted by HS-SPME from (A) red, (B) orange and (C) yellow fruits. (See Table 1 for peak identification). 
Table 1. Retention times (RT) and chromatographic area percentages of the volatile components extracted from red, orange and yellow ginseng fruits using HS-SPME-GC-MS.

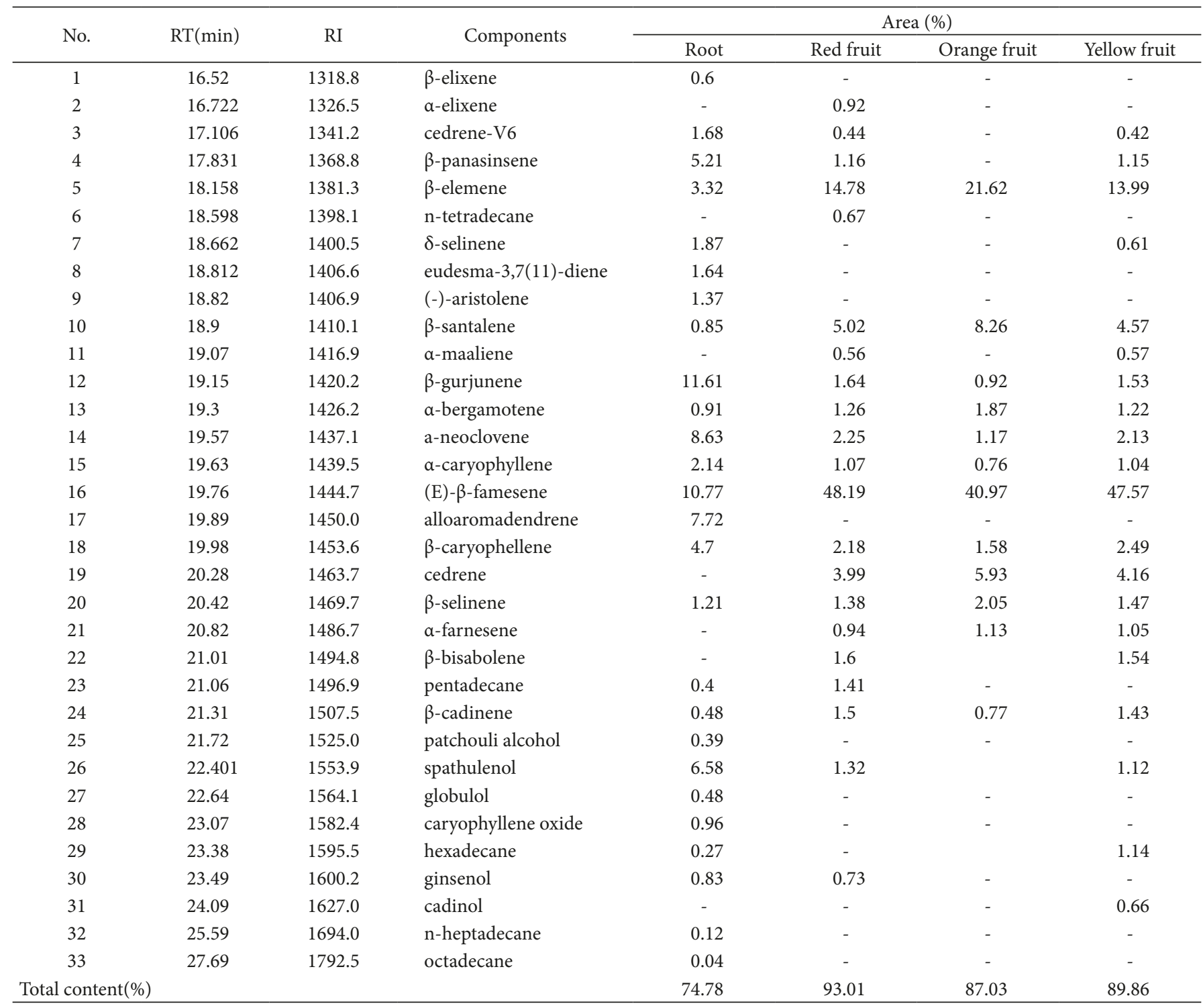

and $\alpha$-neoclovene. In general, sesquiterpenes are strongly associated with the flavor of plants (González-Mas et al., 2019). Most ginseng fruits examined in the present study exhibited a large percentage of sesquiterpenes (86.94-88.90). Especially, the levels of main sesquiterpenes (e.g., (E)- $\beta$-famesene, $\beta$-elemene, santalene and cedrene) identified in the present study, are higher in ginseng fruits than in ginseng roots, except for $\alpha$-neoclovene. On the other hand, the total levels of sesquiterpenes are the highest in red fruits, followed by orange fruits. It is also notable that cedrene and $\alpha$-farnesene are dominant in ginseng fruits, but aren't detected in ginseng roots.

On the basis of previous studies, sesquiterpene hydrocarbons, long chain saturated fatty acids and esters are major volatile components of ginseng root. However, in this study, the volatile components in dried fruits and roots confirmed by HS-SPME coupled with GC-MS are significantly different that of ginseng root. And volatile oil of the fresh ginseng fruits was investigated by steam distillation with GC-MS. In their study, 26 components were isolated, aliphatic components occupy a high proportion (76.9) in the identified components, while the terpenes percentage(ratio)is 15.4, linoleicacid ethyl ester (24.88) and hexadecanoic acid ethyl ester (24.17) are high content in aliphatic components of ginseng fruits. These disparate findings might be attributable to the sample preparations, extraction methods, and other factors differing between the studies. In particular, the HS-SPME extraction method, which has been applied widely, could conduce to extract more sesquiterpenes.

\subsection{Comparision of the volatiles composition of fruits}

Principal components analysis (PCA) is one of the most important methods for dimensionality reduction, the central idea of PCA is to reduce the dimensionality of a data set consisting of a large number of interrelated variables, while retaining as much as possible of the variation present in the data set. This is 
achieved by transforming to a new set of variables, the principal components (PCs), which are uncorrelated, which are ordered so that the first few retain most of the variation present in all of the original variables, and which each principal component can reflect most of the information of the original variables. At present, principal component analysis is widely used in the field of food, mainly for food flavor, food quality and food authentication (Callao \& Ruisanchez, 2018; Granato et al., 2018). In this paper, $\mathrm{PCA}$ is performed using the relative percentage of volatile components and the fruit color of different fruits as data sources, the relationship between the ginseng fruits and the volatile components is investigated by applying PCA to the complex GC-MS data sets. In PCA, 1st factor or principal component (PC) is extracted, which explains the largest amount of variation among the ginseng fruits. The second $\mathrm{PC}$ is then derived to account for the maximum variation in the remaining unexplained variability. Each PC is a linear combination of the original variables (volatiles). The relationship between the original variables and the samples (fruits colors) can then be observed by their projection on these few PCs. The 24 volatile compounds of fruits were identified in HS-SPME analysis, the original data were pre-processed by averaging before PCA. PCA was applied to the mean attribute score listed in Table 1 to simplify interpretation of data from the volatile compounds measured from 6 products from 3 different fruit colors. The correlation between fruits and PC were shown in Figure 2A, instead of the table of loading scores for the fruits. And the correlation between volatile compounds and PC was shown in Table 2 and Figure 2B. In Figure 2A, the fruits were obviously spreads on the PC 1 and 2 and it can be grouped, according to colors in the score plots constructed by combining PC1 (80.8\%) with PC2 (19.2\%). Orange fruits are preferentially separated from red and yellow fruits by PC1 in this score plot, whereas red and yellow fruits are separated from each other by PC2. In Figure 2B, most of volatile compounds lie on the positive and negative regions of PC1 and PC2.

In correlation between fruits and volatile components, $\beta$-elemene, $\beta$-santalene, $\alpha$-bergamotene, cedrene and $\beta$-selinene were correlated with orange fruits, which are higher positive values in the PC1 loading plot. These results means that the area ratios of $\beta$-elemene, $\beta$-santalene, $\alpha$-bergamotene, cedrene, $\beta$-selinene in orange fruits were higher than those in red and yellow fruits. On the other hand, $\alpha$-elixene, tetradecane and pentadecane,
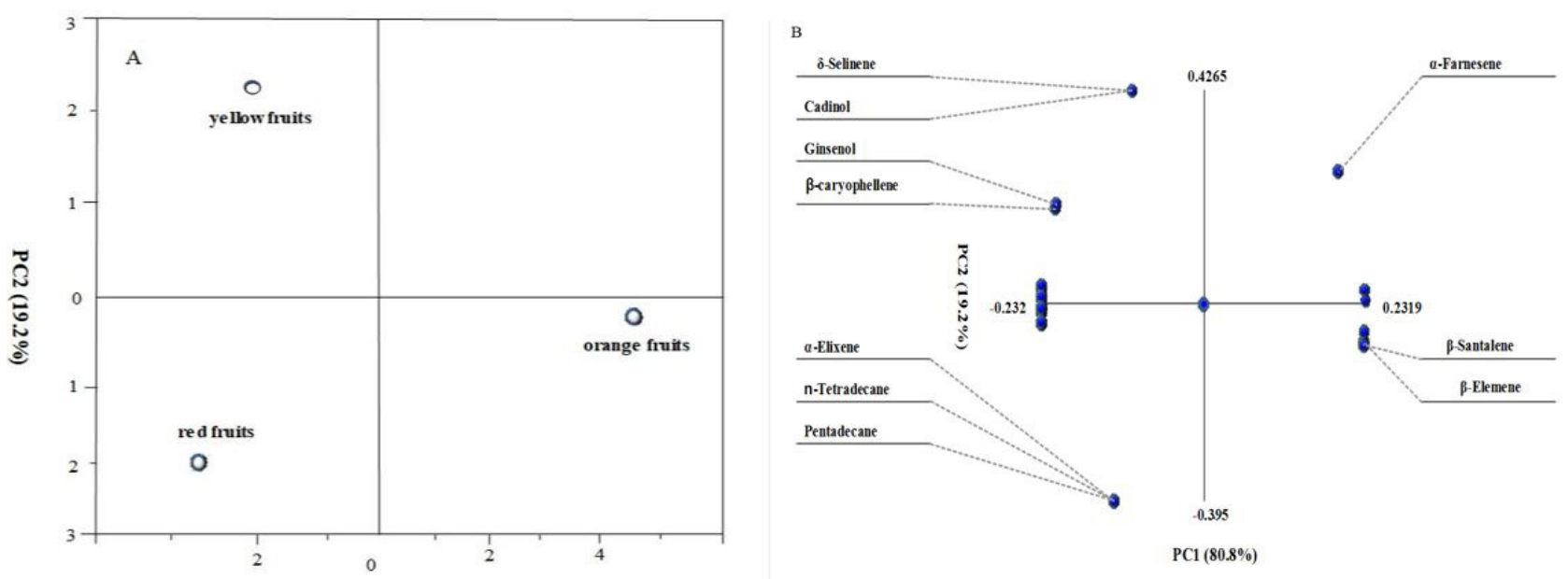

Figure2. Plot of PCA of peak area ratio of characteristic volatile compound extracted from ginseng fruits by using solid-phase microextraction (SPME) method according to different gruits colors. PC1 compared to PC2 scatter plot of the main sources of variability (A) between the fruits colors and (B) between the volatile components.

Table 2. PCA results of peak area ratio of characteristic volatile compound extracted from ginseng fruits by using HP-SPME method according to different colors.

\begin{tabular}{|c|c|c|c|c|c|}
\hline Compound name & PC1 & $\mathrm{PC} 2$ & Compound name & $\mathrm{PC1}$ & $\mathrm{PC} 2$ \\
\hline a-elixene & -0.13 & -0.4 & (E)- $\beta$-famesene & -0.23 & -0.01 \\
\hline cedrene-V6 & -0.23 & 0.01 & $\beta$-caryophyllene & -0.21 & 0.19 \\
\hline$\beta$-panasinsene & -0.23 & 0.03 & cedrene & 0.23 & 0.01 \\
\hline beta-elemene & 0.23 & -0.08 & $\beta$-selinene & 0.23 & 0.03 \\
\hline n-tetradecane & -0.13 & -0.4 & $a$-farnesene & 0.19 & 0.26 \\
\hline$\delta$-selinene & -0.1 & 0.43 & $\beta$-bisabolene & -0.23 & 0.01 \\
\hline$\beta$-santalene & 0.23 & -0.08 & pentadecane & -0.13 & -0.4 \\
\hline maaliene & -0.23 & 0.04 & $\beta$-cadinene & -0.23 & -0.01 \\
\hline$\beta$-gurjunene & -0.23 & -0.04 & spathulenol & -0.23 & -0.04 \\
\hline a-bergamotene & 0.23 & -0.06 & ginsenol & -0.21 & 0.2 \\
\hline a-neoclovene & -0.23 & -0.02 & cadinol & -0.1 & 0.43 \\
\hline a-caryophyllene & -0.23 & -0.01 & & & \\
\hline
\end{tabular}


$\beta$-gurjunene, $\alpha$-neoclovene, $\alpha$-caryophyllene, (E)- $\beta$-famesene, $\beta$-cadinene and spathulenol, which indicate higher negative values of $\mathrm{PC} 2$ and $\mathrm{PC} 1$, are clustered together in red fruits, these compounds were present in a relatively higher concentration in red fruits than in yellow fruits. whereas yellow fruits are found to contain more $\delta$-selinene, cadinol, $\beta$-caryophyllene, $\alpha$-farnesene, and ginsenol, with higher positive values in the PC2 loading plot. In this study, the separations among the different color fruits of the samples from this PC1-PC2 scatter point plot are obvious.

\section{Conclusion}

Sesquiterpenes are predominantly volatile components detected from ginseng fruits, which also bring the unique flavor and aroma in ginseng. In the present work, two sample extraction (HS-SPME) and analysis techniques (GC-MS) are successfully combined and applied to extraction of ginseng volatile components in ginseng fruits. Moreover, we establish the first overview of ginseng volatile compounds profile, characteristic for red fruit, yellow fruit and orange fruit ginseng. This method, with a powerful technique, could analyze and characterize ginseng volatile components rapidly, and it would be a simple, inexpensive and rapid way. Moreover, PCA was useful for grouping volatile components by fruits color. Orange fruits are preferentially separated from red and yellow fruits by $\mathrm{PC} 1$ in this score plot, whereas red and yellow fruits are discriminated from each other by PC2. In summary, sesquiterpenes are the main volatile components in ginseng fruits such as (E)- $\beta$-famesene, $\beta$-elemene, santalene, cedrene and $\alpha$-neoclovene, and the total levels of sesquiterpenes are the highest in red fruits, followed by orange and yellow fruits in the present study, which would promote utilization, quality evaluation in ginseng fruits and breeding program of panax ginseng.

\section{Acknowledgements}

The authors are grateful to the financial support by the Science and Technology Innovation Project of Chinese Academy of Agricultural Scienes under CAAS-ASTIP-2016-ISAPS, the Science and Technology Development Plan Project of Jilin province under 20160307002YY.

\section{References}

Abd El-Aty, A. M., Kim, I. K., Kim, M. R., Lee, C., \& Shim, J. H. (2010). Determination of volatile organic compounds generated from fresh, white and red Panax ginseng (C. A. Meyer) using a direct sample injection technique. Biomedical Chromatography, 5(5), 556-562. PMid:18205137.

Bajer, T., Surmová, S., Eisner, A., Ventura, K., \& Bajerová, P. (2018). Use of simultaneous distillation-extraction, supercritical fluid extraction and solid-phase microextraction for characterisation of the volatile profile of Dipteryx odorata (Aubl.) Willd. Industrial Crops and Products, 119, 313-321. http://dx.doi.org/10.1016/j. indcrop.2018.01.055.

Callao, M. P., \& Ruisanchez, I. (2018). An overview of multivariate qualitative methods for food fraud detection. Food Control, 86, 283-293. http://dx.doi.org/10.1016/j.foodcont.2017.11.034.

Costa, N. R., Cappato, L. P., Ferreira, M., Pires, R. P. S., Moraes, J., Esmerino, E. A., Silva, R., Neto, R. P. C., Tavares, M. I. B., Freitas, M. Q., Silveira Júnior, R. N., Rodrigues, F. N., Bisaggio, R. C., Cavalcanti,
R. N., Raices, R. S. L., Silva, M. C., \& Cruz, A. G. (2018). Ohmic Heating: A potential technology for sweet whey processing. Food Research International, 106, 771-779. http://dx.doi.org/10.1016/j. foodres.2018.01.046. PMid:29579986.

Coutinho, N. M., Silveira, M. R., Fernandes, L. M., Moraes, J., Pimentel, T. C., Freitas, M. Q., Silva, M. C., Raices, R. S. L., Ranadheera, C. S., Borges, F. O., Neto, R. P. C., Tavares, M. I. B., Fernandes, F. A. N., Fonteles, T. V., Nazzaro, F., Rodrigues, S., \& Cruz, A. G. (2019). Processing chocolate milk drink by low-pressure cold plasma technology. Food Chemistry, 276, 276-283. http://dx.doi.org/10.1016/j. foodchem.2018.11.061. PMid:30583374.

González-Mas, M. C., Rambla, J. L., López-Gresa, M. P., Blázquez, M. A., \& Granell, A. (2019). Volatile compounds inCitrus essential oils: A comprehensive review. Frontiers of Plant Science, 10, 12. http:// dx.doi.org/10.3389/fpls.2019.00012. PMid:30804951.

Granato D, Putnik P, Danijela B K, Santos J S, Calado V, Rocha R S, Cruz A G D, Jarvis B, Rodionova O Y, Pomerantsev A. 2018. Trends in Chemometrics: Food Authentication, Microbiology, and Effects of Processing, 17, 663-667.

Jiang, M., Li, H., Shi, J. S., Shi, Y. D., \& Xu, Z. H. (2018). Analysis of volatile compounds in Chuju and Chuju formula granule by headspace solid-phase microextraction coupled to gas chromatography-mass spectrometry. Anhui Yiyao, 22, 611-615.

Martins, C. P. C., Ferreira, M. V. S., Esmerino, E. A., Moraes, J., Pimentel, T. C., Rocha, R. S., Freitas, M. Q., Santos, J. S., Ranadheera, C. S., Rosa, L. S., Teodoro, A. J., Mathias, S. P., Silva, M. C., Raices, R. S. L., Couto, S. R. M., Granato, D., \& Cruz, A. G. (2018). Chemical, sensory, and functional properties of whey-based popsicles manufactured with watermelon juice concentrated at different temperatures. Food Chemistry, 255, 58-66. http://dx.doi.org/10.1016/j. foodchem.2018.02.044. PMid:29571498.

Mattje, L. G. B., Tormen, L., Bombardelli, M. C. M., Corazza, M. L., \& Bainy, E. M. (2019). Ginger essential oil and supercritical extract as natural antioxidants in tilapia fish burger. Journal of Food Processing and Preservation, 43(2), e13942. http://dx.doi.org/10.1111/jfpp.13942.

Misharina, T. A., Terenina, M. B., Krikunova, N. I., \& Mihailov, I. A. (2018). Effect of the compositions of sample and polymer sorbents on the extraction of volatile compounds by solid-phase microextraction. Applied Biochemistry and Microbiology, 54(1), 89-97. http://dx.doi. org/10.1134/S0003683818010052.

Shi, M. Y., Zhao, S. T., Wen, C. B., \& Li, X. F. (2018). Study on the status of product development of fruit of panax ginseng. Asia-Pacific Traditional Medicine, 14, 59-61.

Silveira, M. R., Coutinho, N. M., Esmerino, E. A., Moraes, J., Fernandes, L. M., Pimentel, T. C., Freitas, M. Q., Silva, M. C., Raices, R. S. L., Senaka Ranadheera, C., Borges, F. O., Neto, R. P. C., Tavares, M. I. B., Fernandes, F. A. N., Fonteles, T. V., Nazzaro, F., Rodrigues, S., \& Cruz, A. G. (2019). Guava-flavored whey beverage processed by cold plasma technology: Bioactive compounds, fatty acid profile and volatile compounds. Food Chemistry, 279, 120-127. http://dx.doi. org/10.1016/j.foodchem.2018.11.128. PMid:30611471.

Tao, L., Li, K. K., Li, D. X., \& Gong, X. J. (2018). Saponin constituents from fruits of Panax ginseng. Zhongguo Xiandai Zhongyao, 20, 928-937.

Tuan, D. Q., Duc, H. V., Nhan, L. T., Anh, L. T., Hoai, N. T., \& Raal, A. 2019. Constituents of Essential Oils from the Leaves of Paramignya trimera (Oliv.) Guillaum from Vietnam. Journal of Essential OilBearing Plants, 22(2), 391-395.

Turgumbayeva, A. A., Ustenova, G. O., Yeskalieva, B. K., Ramazanova, B. A., Rahimov, K. D., Aisa, H., \& Juszkiewicz, K. T. (2018). Volatile oil composition of Carthamus Tinctorius L. flowers grown in Kazakhstan. Research Journal of Pharmaceutical, Biological and Chemical Sciences, 6(2), 125-129. PMid:29575869. 